\title{
Rauwolfia Vomitoria and Vitamin E Restore Impaired Learning and Memory in 3-Nitropropionic Acid-Induced Oxidative Stressed Mice
}

Agnes Igimi 0², Ezekiel I², Eze Ejike D ${ }^{3 *}$, Moses Adams D, Afodun

Adam $\mathbf{M}^{5}$, Karimah Mohammed $\mathbf{R}^{6}$, Quadri Khadijah $\mathbf{K}^{7}$ and Okpanachi Alfred $\mathbf{O}^{3}$

${ }^{1}$ Department of Physiology, Faculty of Basic Medical Sciences, Cross River University of Technology, Nigeria

${ }^{2}$ Department of Biological Sciences, Faculty of Pure and Applied Sciences, Federal University, Wukari, Nigeria

${ }^{3}$ Department of Physiology, Faculty of Biomedical Sciences, Kampala International University, Uganda

4 Department of Biochemistry, Faculty of Science and Technology, Bingham University, Nigeria

${ }^{5}$ Department of Anatomy, Faculty of Biomedical Sciences, Kampala International University, Uganda

${ }^{6}$ Department of Biological Sciences, Faculty of Science, Yobe State University, Nigeria

${ }^{7}$ Department of Physiology, College of Medicine, University of Lagos, Nigeria

*Correspondence author: Eze Ejike Daniel, PhD; Department of Physiology, Faculty of Biomedical Sciences, Kampala International University, Western Campus, Ishaka-Bushenyi, Uganda, Tel: +256782975042; Email: daniel.ejike@kiu.ac.ug

\section{Abstract}

The effect of root bark extract of Rauwolfia vomitoria (RV) and Vitamin E on neurobehaviour in 3-nitropropionic acidinduced oxidative stress (OS) in mice was evaluated. Forty mice were divided into four groups (1-4) of 10 mice each. Animals in group one (control rats) received placebo treatment. Animals in group two were induced into oxidative stress by intraperitoneal injection (i.p) with $20 \mathrm{mg} / \mathrm{kg}$ body weight of 3-nitropropionic acid (3NP) once daily for 5 days. Animals in group three were pre-treated orally with $16 \mathrm{mg} / \mathrm{kg}$ body weight of root bark extract of $R$. vomitoria before being treated with $20 \mathrm{mg} / \mathrm{kg}$ body weight of 3NP (i.p) for 15 days. Animals in group four were pre-treated orally with $10 \mathrm{mg} / 100 \mathrm{~g}$ of Vitamin E (VE) before being treated with $20 \mathrm{mg} / \mathrm{kg}$ body weight of 3NP (i.p). The Morris water maze $(\mathrm{MWM})$ test was done to determine the learning and memory status of the mice. There was significant $(\mathrm{P}<0.05)$ longer swim latencies particularly for days 2 and 3 of the acquisition training in the $3 \mathrm{NP}$-induced oxidative stress group of mice when compared to the control group, RV treated 3NP OS group and vitamin E treated 3NP OS group. Findings from the reversal training swim latency, acquisition quadrant, retention quadrant duration, annulus acquisition frequency, 


\section{International Journal of Biochemistry \& Physiology}

frequency of annulus reversal and visible platform task showed a significant increase $(P<0.05)$ in the swim latency of $\mathrm{RV}+3 \mathrm{NP}$ OS group when compared with the control and the VE+3NP OS group and a decrease in 3NP OS when compared with the VE+3NP OS and the control group. Treatment of these 3NP-induced oxidative stressed mice with root bark extract of $R$. vomitoria and Vitamin E reversed this cognitive learning and memory impairments toward normal, with $R$. vomitoria being more potent in ameliorating the effect of oxidative stress on learning and memory.

Keywords: Rauwolfia vomitoria; Apocynaceae; Morris Water Maze; Swim Latency; 3-Nitropropionic Acid; Learning; Memory

Abbreviations: RV: Rauwolfia vomitoria; MWM: Morris water maze; 3NP: 3-nitropropionic acid; VE: Vitamin E; OS: Oxidative stress; I.P: Intraperitoneal injection; HD: Huntington's diseases; ITs: Inter-trial intervals; SEM: Standard error of Mean.

\section{Introduction}

Learning can be defined as the process by which new information is acquired [1]. The brain is unique in its ability to add to its stock of information. Learning alters the behaviour of an individual on the basis of past experience. The receipt, storage and retrieval of information are general properties of neuronal networks that serve to adapt individual behaviour to the environment [2]. One of the major parts of the brain involved in learning and memory is the hippocampal information, which includes the subiculate cortex, the hippocampal itself and the dentate gyrus [3]. Intense electrical stimulation of axons from the hippocampal entorhinal cortex to the dentate gyrus causes a long-term increase in the post synaptic neurons; a strengthening called "long term potentiation" [4]. Learning is of two types; associative learning and non-associative learning. Associative learning involves learning about relations between two or more stimuli at a time. Non-associative learning involves the response of a person to only one type of stimulus. It may be based on two factors which include; habituation and sensitization. Habituation is a simple form of learning in which a neural stimulus is repeated many times. Sensitization involves an increase in response to an innocuous stimulus when it applied after another type of stimulus. It can also be called the application of response or sensitization [1].

Memory is the retention and retrieval of information. Without the ability to learn, retain and retrieve items by way of memory, it will be impossible to plan and such, plans successfully. Physiologically, memories are caused by changes in the sensitive of synaptic transmissions between neurons as a result of previous neural activity. These changes in turn cause few pathways or facilitate old ones to enhance transmission of signals through them. These new facilitated pathways are called memory trace or engrams [5]. Memory is usually divided into short term and long-term memory base on time scale. Short term memory stores information for seconds to minutes and perhaps, a few hours. Long-term memory (remote memory) stores information for hours, days, months and even years [6]. Disorders of memory include amnesia (anterograde and retrograde) and dementia [7].

3-Nitropropionic acid (3NP) is a natural environmental toxin obtained from various plants, fungi and induces Huntington's diseases (HD) like symptom both in humans and experimental animals [8]. Therefore, 3NP has been proposed to cause both cellular and mitochondrial stress. Some reports suggest the involvement of oxidative stress initially as a prime candidate mediating behavioral impairment and memory deficits in age related neurodegenerative disorders. 3NP produces selective lesions in basal ganglia (striatum), cortex, hippocampus and produce dystonia in human $[9,10]$.

Vitamin $\mathrm{E}$ is a fat-soluble vitamin that occurs in nature and function as an antioxidant by intercepting free radicals generated during normal metabolic process [11]. It consists of two families of compounds, the tocopherols and tocotrienols, characterized by a 6-chromanol ring and an isoprenoid side chain. Vitamin E deficiency occurs only as a result of genetic abnormalities in $\alpha$-tocopherol transfer protein, as a result of various fat mal-absorption syndromes, or as a result of protein-energy malnutrition [12]. 


\section{International Journal of Biochemistry \& Physiology}

Rauwolfia vomitoria is a species of flowering plant and belong to the family of Apocynaceae. Its common names include African Serpent Wood, African Snakeroot and Swizzle Stick. In Nigeria local languages, it is called Asofeyeje (Yoruba), Akata (Bini), Ira (Igbo), Eto mmoneba/utoenyin (Efik and Ibibio) and Wadda (Hausa) respectively [13]. The plant is a small shrub, which grows up to $15 \mathrm{~m}$ high and has oval or oblong shiny leaves in whorls and with straight veining and a cluster of inconspicuous white or greenish flowers producing red berries. The wood is white when freshly cut, changes to rose colour on exposure. The roots are tuberous with pale brown cork. The shrub is an ever-green perennial plant. It is extensively grown in most tropical forest of pacific, South America, Asia, Congo and Africa on commercial basis for its medicinal value. In Nigeria, it is found near Lagos, Abeokuta, Ibadan, Calabar, Akamkpa and Odukpani Local Government Area of Cross River State [14,15]..

R. vomitoria is used in insanity, anxiety and stimulant to CNS [16]; antipyretic and analgesic [17,18]; anticonvulsant and antipsychotic $[19,20]$; sedatives $[21,22]$; anti-inflammatory effect [23]; antidiabetic effect [24]; anti-cardiovascular [25]; and anti-cancer effect [26].

Bisong, et al. [27] reported that the aqueous root bark extract of $R$. vomitoria at $0.0,0.25,1.0,2.0,4.0 \mathrm{mg} / \mathrm{kg}$ body weight has a high potential as an antipsychotic than chlorpromazine. Apart from this, study on comparative effect of the plant at $16 \mathrm{mg} / \mathrm{kg}$ body weight and vitamin $\mathrm{E}$ on learning and memory has not been reported. Therefore, this study was designed to evaluate the comparative effect of root bark extract of Rauwolfia vomitoria on learning and memory in 3-nitropropionic acid-induced oxidative stress in mice.

\section{Materials and Methods}

\section{Materials}

\section{Plant materials and authentication}

Root bark of Rauwolfia vomitoria were collected from the Botanical Garden of the University of Calabar, Cross River State, Nigeria and authenticated with voucher specimen MIA 2004.

\section{Experimental animals}

The animals used were albino mice purchased from the Department of Physiology. The mice were housed in the animal house of the Department of Physiology under a 12/12hour day light/dark cycle and normal room temperature. All animals were given free access to rodent feed and clean drinking water. Beddings of the cages were changed every other day.

\section{Drugs and chemicals}

They include: 3-Nitropropionic acid and vitamin E which are products of (Sigma Int'l.) and Mason Vitamin E; $1000 \mathrm{IU}$ (667mg) tablet respectively. Other chemicals, reagents and normal saline $(0.9 \%)$ were of analytical grade (JHD, China).

\section{Methods}

\section{Preparation of root bark extract of Rauwolfia vomitoria}

The extraction of the root bark of Rauwolfia vomitoria was done according to the method of Bisong, et al. [20]. The roots of the plant (Rauwolfia vomitoria) were harvested from the Botanical Garden of the University of Calabar and cleaned with water. The dead cells covering the roots were removed and the succulent part of the root bark were carefully removed and dried in the sun. The sun-dried root bark was then grinded to very fine powder form and stored in an air-tight container until required for use. Four hundred grams (400 g) of the powder root back were mixed in one liter of distilled water and allowed to sit for at least 2 hours. The mixture was then filtered using Whatman no. 1 filter paper before the filtrate was evaporated using the rotary evaporator. The evaporated thick paste was stored in a refrigerator and prevented from direct contact with sunlight until required for use (administration to the animal).

\section{Experimental design and animal treatment}

Forty mice in all were used for the experiments. The mice were divided into four groups of 10 mice each. Animals in the first group formed the control group and they received placebo treatment. Mice in the second group were treated with 3-Nitropropionic acid (3NP) at a dose of $20 \mathrm{mg} / \mathrm{kg}$ via intra-peritoneal injections once daily for five days. This treatment was to induce oxidative stress in the mice. The mice in the third group of were pre-treated with the extract of $R$. vomitoria $(16 \mathrm{mg} / \mathrm{kg}$ orally) for 5 days before being treated with 3-NP $(20 \mathrm{mg} / \mathrm{kg})$ to induce oxidative stress. The $3 \mathrm{NP}$ was administered once daily for five days while the treatment with $R$. vomitoria continued through the period until another fifteen days. Mice in the fourth group were pretreated with vitamin $\mathrm{E}$ at a dose $10 \mathrm{mg} / 100 \mathrm{~g}$ of body weight per day (orally) for 5 days before treating with $3 \mathrm{NP}(20 \mathrm{mg} / \mathrm{kg}$, i.p.) to induce oxidative stress once daily for five days. Administration of vitamin $\mathrm{E}$ was continued until another fifteen days. At the end of this treatment 


\section{International Journal of Biochemistry \& Physiology}

period, the animals were subjected to behavioural testing to assess any changes in behaviour.

\section{Behavioural Assay}

The morris water maze: The Morris water maze (MWM) consists of a circular pool filled with opaque water. Mice were trained to use extra-maze visual cues to locate an escape platform hidden just below the surface of the opaque water (Morris, 1984). The hidden-platform version of the MWM is a test of visuo-spatial learning and memory, performance of which is impaired by hippocampal lesions [28].

The water maze was made out of a circular polypropylene pool measuring $110-\mathrm{cm}$ in diameter and $20-\mathrm{cm}$ in depth. The pool was filled to a depth of $14-\mathrm{cm}$ (0.5-cm over the platform) with room-temperature tap water, which is made opaque by adding smoothly grinded non-toxic white chalk. The water was left to sit overnight in order to reach room temperature $25 \pm 2^{\circ} \mathrm{C}$ ).

The pool is divided into four quadrants: Northwest, Northeast, Southwest and Southeast. Boundaries of these quadrants are marked on the edges of the pool with masking tape and labelled: North, South, East and West. A cylindrical cement block ( $13.75 \mathrm{~cm} \times 9 \mathrm{~cm}$ diameter) was used as the escape platform in the maze. The platform has a removable red and yellow striped top $(3 \mathrm{~cm} \times 9 \mathrm{~cm}$ in diameter) with a colorful flag erected in the center. For visible platform tests the level of the water in the pool is adjusted to $0.5-\mathrm{cm}$ below the surface of the striped top, thus creating a visible escape platform, or to $0.5-\mathrm{cm}$ above the white cylinder (with the striped top removed), creating a hidden escape platform.

\section{Procedure:}

The Morris water maze test consisted of 8 days:

Day 1: Acquisition day 1

Day 2: Acquisition day 2

Day 3: Acquisition day 3

Day 4: Reversal day 1

Day 5: Reversal day 2

Day 6: Reversal day 3

Day 7: Probe trial

Day 8: Visible-platform day

Acquisition and reversal training were with the hidden platform (water is $0.5-\mathrm{cm}$ above platform). During reversal, the platform was moved to the opposite side of the maze. During the probe trial, there was no escape platform so that visuo-spatial memory can be assessed. On the visible-platform day the platform was moved to another quadrant of the pool and the visible top is added to the platform. This assessed basic visual ability and motivation to locate the platform.

On each day of the test, the mouse was removed from its home cage and was placed in a clean holding cage without woodchip bedding. Paper towel was torn into strips and placed in the bottom of the holding cages to allow the mice to dry more quickly. This paper towel was replaced when it becomes wet. Mice were run in squads of 4-6 with 5-minutes between each trial (inter-trial interval) for each mouse. It is important not to use shorter inter-trial intervals (ITIs), as a short ITI can produce performance deficits in mice due to hypothermia [29].

During acquisition training, the platform was placed in the center of the Northeast quadrant. Each mouse receives 4 trials per day. In each trial, the mouse was given a maximum of 60-sec to locate the escape platform. The starting positions of the mice were predetermined using a Latin square design, which prevented the repetition of starting location sequences on back-to-back test days (Table 1). Possible start positions were at the boundaries of the quadrants (e.g. West, North, East or South). For each trial, each mouse was removed from its holding cage using a small, clean $500-\mathrm{mL}$ plastic container to minimize handling stress. The animal was then placed into the water at the appropriate start position. [Note: some care should be taken to ensure that the mouse's head does not go underwater. Some mice, if their head goes underwater, go into a "dive reflex" and drop to the bottom of the pool. If this happened the mouse was taken out of the water, held it on the hand and pressed gently on its stomach in pulses - artificial respiration - and put it back in its home cage and retested as the last mouse of the squad].

At each trial, the mouse was permitted to explore the pool and to search for the hidden escape platform for 60 sec. When the animal locates the platform, the timer was stopped (manually) and the mouse allowed to stay on the platform. Once on the platform, the mice were permitted to view the extra-maze environment for 10 -sec, at which point the mouse was picked up the in the plastic container and returned to the appropriate holding cage. It is important to only remove the mouse after it is on the platform so that it associates the platform with escape. If the mouse did not find the platform during the allotted time, the animal was guided onto the platform using the back of the plastic container. And once on the platform it was allowed 10 second to view extra maze cues. The next 


\section{International Journal of Biochemistry \& Physiology}

mouse was then placed in the pool and the same procedure followed. Each animal completed 4 trials per day over 3 days, for 12 trials of acquisition training, each trial from a different one of the 4 start locations.

Reversal training began on day 4. The invisible platform is moved to the opposite quadrant (Southwest quadrant), and mice were again assigned to appropriate start positions. The same procedures as in acquisition training were carried out during reversal training. Each of the animals completed 4 trials per day for 3 days for a total of 12 trials of reversal training.

A probe trial was conducted on day 7 to assess visuospatial memory. At this time, there is no escape platform in the maze. Each mouse was placed in the pool from one of the four possible start positions and allowed to explore the pool for 60 -sec, during which the time spent in each quadrant of the maze was recorded. When the 60-sec was completed, the mouse was scooped up using the container which was placed in a holding cage to dry before being returned to its home cage.
The visible platform task was conducted on day 8 . The visible platform was placed in a new location within the Northwest quadrant of the pool. The same procedures as in acquisition and reversal training are carried out and mice complete 4 trials.

The behaviour scored during the Morris water maze test included:

1. Swim latency - the time it took the mouse to locate the hidden platform during the acquisition and reversal training (these were charted against the days of training both for acquisition and reversal training), and visible platform task.

2. Quadrant duration - the amount of time spent in each quadrant during the probe trial

3. Annulus acquisition crossing - number of time the animal crossed the position of the platform at the acquisition training during the probe trial.

4. Annulus reversal crossing - number of times the animal crossed the position of the platform at the reversal training during the probe trial [30].

\begin{tabular}{|c|c|c|c|c|c|}
\hline Mice Group & Day & Location 1 & Location 2 & Location 3 & Location 4 \\
\hline 1 & 1 & $\mathrm{~N}$ & S & $\mathrm{E}$ & $\mathrm{W}$ \\
\hline 1 & 2 & $\mathrm{E}$ & $\mathrm{W}$ & $\mathrm{S}$ & $\mathrm{N}$ \\
\hline 1 & 3 & $\mathrm{~W}$ & $\mathrm{E}$ & $\mathrm{N}$ & $\mathrm{S}$ \\
\hline 2 & 1 & $\mathrm{~S}$ & $\mathrm{~N}$ & $\mathrm{~W}$ & $E$ \\
\hline 2 & 2 & $\mathrm{~N}$ & W & $S$ & $\mathrm{E}$ \\
\hline 2 & 3 & W & $\mathrm{S}$ & $\mathrm{E}$ & $\mathrm{N}$ \\
\hline 3 & 1 & $\mathrm{~S}$ & E & $\mathrm{N}$ & $\mathrm{W}$ \\
\hline 3 & 2 & $\bar{E}$ & $\mathrm{~N}$ & $\mathrm{~W}$ & $S$ \\
\hline 3 & 3 & $\mathrm{~N}$ & $\mathrm{E}$ & $\mathrm{W}$ & $S$ \\
\hline 4 & 1 & $\mathrm{~S}$ & $\mathrm{~N}$ & $E$ & $\mathrm{~W}$ \\
\hline 4 & 2 & $\mathrm{E}$ & $\mathrm{W}$ & $S$ & $\mathrm{~N}$ \\
\hline 4 & 3 & $\mathrm{~W}$ & $\mathrm{~S}$ & $\mathrm{~N}$ & $E$ \\
\hline 5 & 1 & $\mathrm{~N}$ & $\mathrm{~S}$ & $E$ & $\mathrm{~W}$ \\
\hline 5 & 2 & $\bar{E}$ & $\mathrm{~W}$ & $\mathrm{~S}$ & $\mathrm{~N}$ \\
\hline 5 & 3 & $\mathrm{~W}$ & $E$ & $\mathrm{~N}$ & $\mathrm{~S}$ \\
\hline 6 & 1 & $S$ & $\mathrm{~N}$ & $\mathrm{~W}$ & $E$ \\
\hline 6 & 2 & $\mathrm{~N}$ & $\mathrm{~W}$ & $S$ & $E$ \\
\hline 6 & 3 & $\mathrm{~W}$ & $S$ & $E$ & $\mathrm{~N}$ \\
\hline 7 & 1 & $S$ & $\bar{E}$ & $\mathrm{~N}$ & $\mathrm{~W}$ \\
\hline 7 & 2 & $\mathrm{E}$ & $\mathrm{N}$ & $\mathrm{W}$ & $\mathrm{S}$ \\
\hline 7 & 3 & $\mathrm{~N}$ & $\mathrm{E}$ & $\mathrm{W}$ & $S$ \\
\hline
\end{tabular}

Table 1: Start locations for acquisition, reversal and visible platform training in the MWM. 


\section{International Journal of Biochemistry \& Physiology}

\section{Data Analysis}

Data collected from the experiments were analyzed using the one way analysis of variance (ANOVA) and the post hoc LSD (least square deviation) test to compare a pair of groups. The results were presented as mean \pm SEM. The probability levels of $p<0.05$ for the ANOVA and post hoc tests of pairs of groups were accepted as significant. The computer software SPSS 16.0 and Microsoft Excel 2010 version were used for the analysis.

\section{Results}

Comparison of the effect of $R$. vomitoria and Vitamin E on swim latency during the acquisition training of the
Morris water maze task in $3 \mathrm{NP}$-induced oxidative stressed mice (days 1, 2 and 3) between the control, 3NP OS, RV+ 3NP OS and VE + 3NP OS groups of mice

The swim latency (the time it takes for the mice to swim and locate the hidden platform) during the acquisition training of the Morris water maze task is shown in Figure 1. It is also referred to as the learning curve.

The result below shows significant $(\mathrm{P}<0.05)$ longer swim latencies particularly for days 2 and 3 of the acquisition training in the 3NP-induced oxidative stress group of mice when compared to the control group, RV treated 3NP OS group and vitamin $\mathrm{E}$ treated $3 \mathrm{NP}$ OS group (at least $\mathrm{P}<$ 0.05).

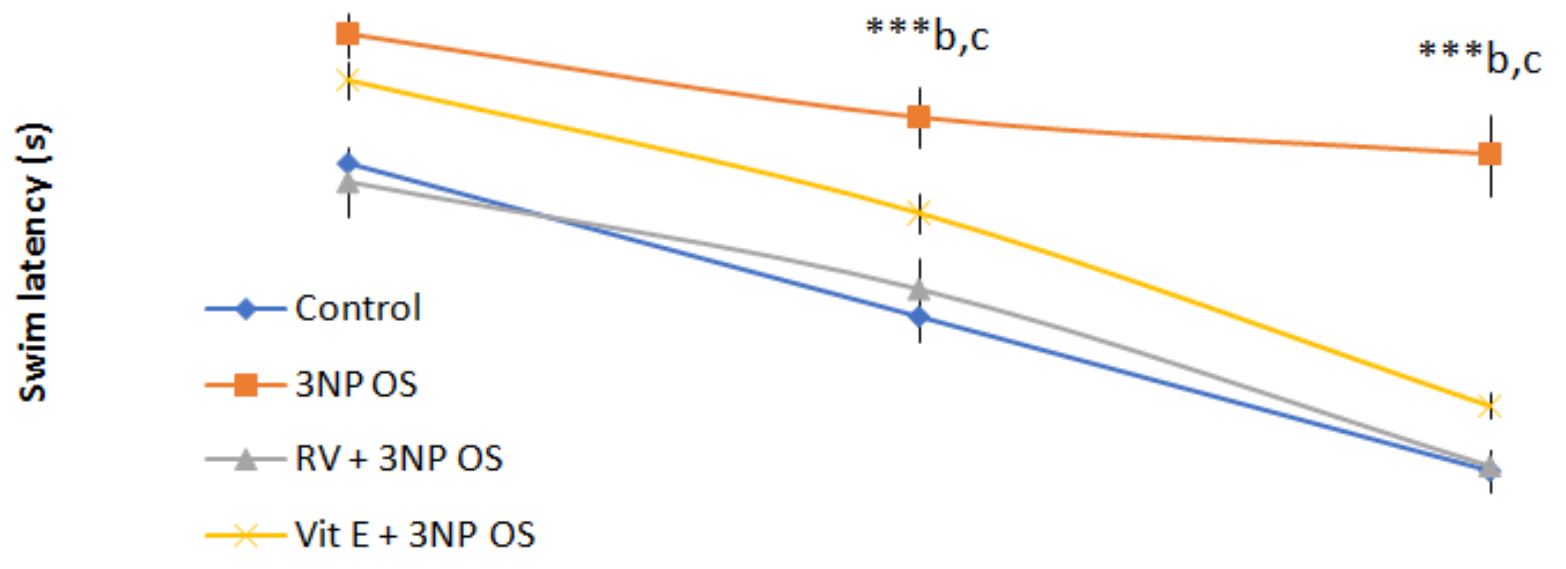

\section{Acquisition training (Days)}

*** - significant at $\mathrm{p}<0.001$ vs control; $\mathrm{b}$ - significant at least $\mathrm{p}<0.05$ vs $\mathrm{RV}+0 \mathrm{O} ; \mathrm{c}-$ significant at least $\mathrm{p}<0.05$ vs vit $\mathrm{E}$ + OS.

Figure 1: Swim latency during the acquisition training periods (days 1, 2 and 3) of the different experimental groups using Morris water maze test.

Values are expressed as mean $\pm \mathrm{SEM}, \mathrm{n}=10$.

Comparison of the effect of $R$. vomitoria and Vitamin E on swim latency during reversal training of the morris water maze task in 3NP-induced oxidative stressed mice (day 4, 5 and 6) between the control, 3NP OS, RV+3NP OS and VE+3NP OS group of mice

The swim latency (the time it takes for the mice to swim and locate the hidden platform) during the reversal training of the Morris water maze task is shown in Figure 2. It is also referred to as the learning curve.

The result below shows high swim latency in the learning curve between 3NP OS and VE+3NP OS and a decrease in the control group and RV+3NP OS. 


\section{International Journal of Biochemistry \& Physiology}

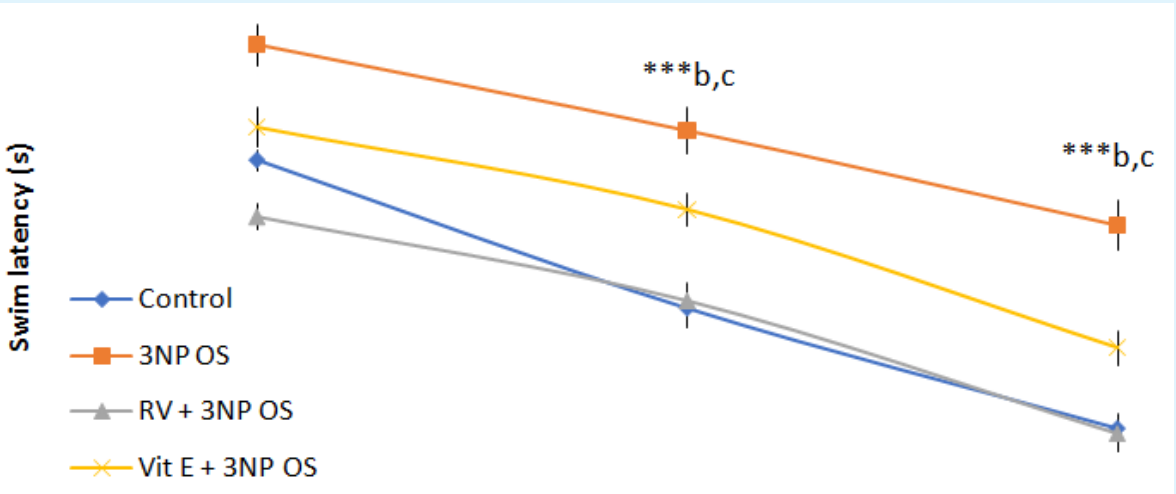

Reversal training (Days)

*** - significant at $\mathrm{p}<0.001$ vs control; $\mathrm{b}$ - significant at least $\mathrm{p}<0.05$ vs $\mathrm{RV}+\mathrm{OS} ; \mathrm{c}$ - significant at least $\mathrm{p}<0.05$ vs vit $\mathrm{E}$ $+\mathrm{OS}$.

Figure 2: Swim latency during the reversal training periods (days 4, 5 and 6) of the different experimental groups using Morris water maze test.

Values are expressed as mean \pm SEM, $n=10$.

Comparison of the effect of $R$. vomitoria and Vitamin $E$ on acquisition quadrant duration at the probe trial of morris water maze in 3NP-induced oxidative stressed mice (day 7) between the control, 3NP OS, RV + 3NP OS and VE+ 3NP OS groups of mice

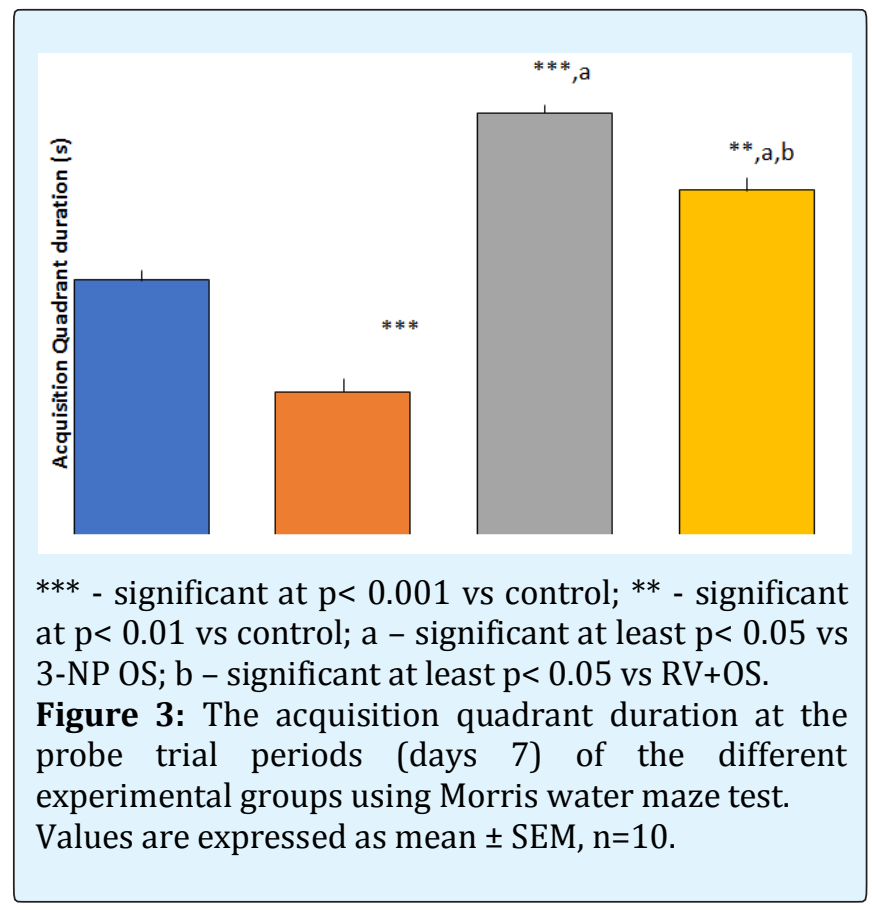

Eze Ejike D, et al. Rauwolfia Vomitoria and Vitamin E Restore Impaired Learning and Memory in 3-Nitropropionic Acid-Induced Oxidative Stressed Mice. Int J Biochem Physiol 2018, 3(4): 000138.
The swim latency (the time it takes for the mice to swim and locate the hidden platform) during the acquisition quadrant duration training of the Morris water maze task is shown in Figure 3. It is also referred to as the learning curve.

The result below shows a significant increase in the swim latency of RV+3NP OS group compare to VE+3NP OS and the control group at $p<0.05$ and there is a decrease in $3 \mathrm{NP}$ OS compare to $\mathrm{VE}+3 \mathrm{NP}$ OS and the control group at $\mathrm{p}<0.05$.

Comparison of the effect of $R$. vomitoria and Vitamin E on retention quadrant duration at the probe trial of Morris water maze in 3NP-induced oxidative stressed mice (day 7) between the control, 3NP OS, RV+3NP OS and VE+3NP OS group of mice

The swim latency (the time it takes for the mice to swim and locate the hidden platform) during the retention quadrant duration training of the Morris water maze task is shown in Figure 4. It is also referred to as the learning curve.

The result below shows a significant increase in the swim latency of RV+3NP OS group compare to VE+3NP OS and the control group at $\mathrm{p}<0.05$ and there is a decrease in 3NP OS compare to VE+3NP OS and the control group at $\mathrm{p}<0.05$. 


\section{International Journal of Biochemistry \& Physiology}

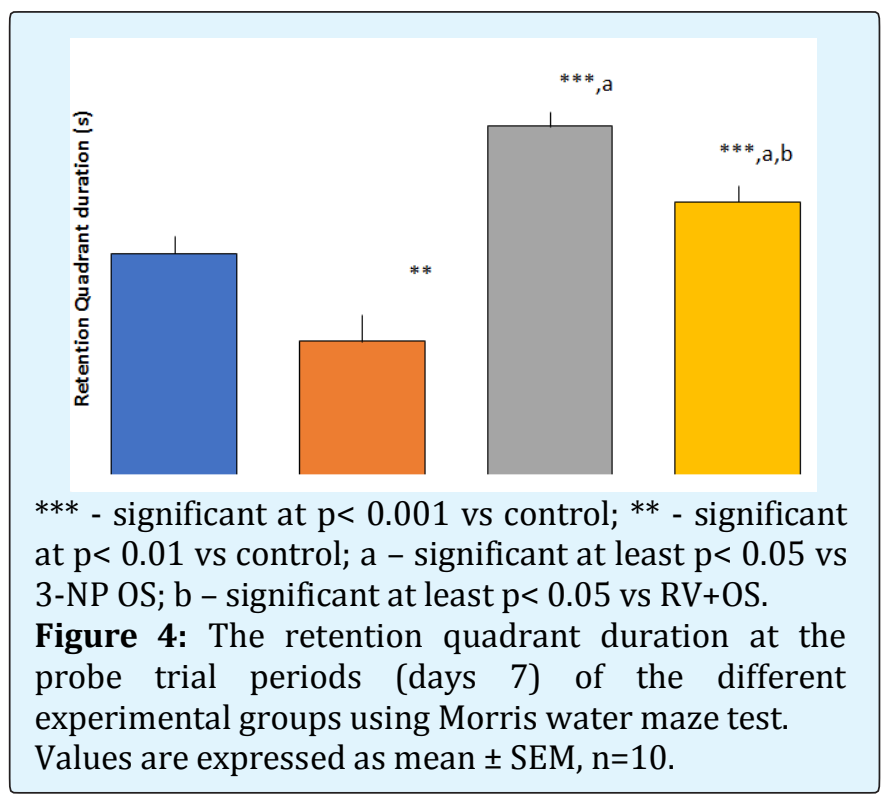

Comparison of the effect of $R$. vomitoria and Vitamin E on annulus acquisition frequency during the probe trial of Morris water maze in 3NP-induced oxidative stressed mice (day 7) between the control, 3NP OS, $R V+3 N P$ OS and VE+3NP OS group of mice

The swim latency (the time it takes for the mice to swim and locate the hidden platform) during the annulus acquisition frequency training of the Morris water maze task is shown in Figure 5. It is also referred to as the learning curve.

The result below shows a significant increase in the swim latency of RV+3NP OS group compare to control and the $\mathrm{VE}+3 \mathrm{NP}$ OS group and there is a decrease in 3NP OS compares to VE+3NP OS and the control group.

(east $\mathrm{p}<0.05$ vs 3-NP OS; $\mathrm{b}$ - significant at least $\mathrm{p}<$
0.05 vs RV+OS.
Figure 5: The annulus acquisitions of the probe trial
periods (days 7) of the different experimental groups
using --Morris water maze test.
Values are expressed as mean \pm SEM, $\mathrm{n}=10$.

Eze Ejike D, et al. Rauwolfia Vomitoria and Vitamin E Restore Impaired Learning and Memory in 3-Nitropropionic Acid-Induced Oxidative Stressed Mice. Int J Biochem Physiol 2018, 3(4): 000138.
Comparison of the effect of $R$. vomitoria and Vitamin E on frequency of annulus reversal during the probe trial of Morris water maze in 3NP-induced oxidative stressed mice (day 7) between the control, 3NP OS, RV $+3 N P O S$ and VE+ 3NP OS groups of mice

The swim latency (the time it takes for the mice to swim and locate the hidden platform) during the annulus reversal training of the Morris water maze task is shown in Figure 6. It is also referred to as the learning curve.

The result below shows a significant increase in the swim latency of RV+3NP OS group compare to control and the $\mathrm{VE}+3 \mathrm{NP}$ OS group and there was a massive decrease in $3 \mathrm{NP}$ OS compares to control and the VE+3NP OS group.

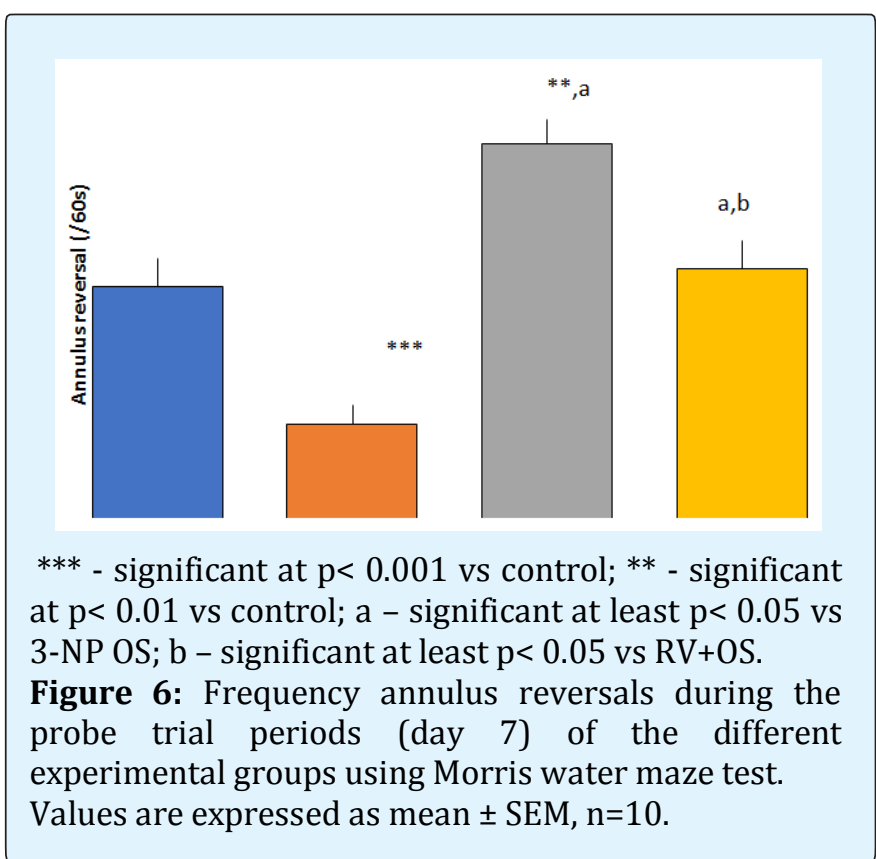

Comparison of the effect of $R$. vomitoria and Vitamin E on swim latency during the visible platform task of the Morris water maze in 3NP-induced oxidative stressed mice (day 8) between the control, 3NP OS, RV + 3NP OS and VE+ 3NP OS groups of mice

The swim latency (the time it takes for the mice to swim and locate the hidden platform) during the acquisition training of the Morris water maze task is shown in Figure 7. It is also referred to as the learning curve.

The result below shows that there was a significant increase in the swim latency of 3NP OS group compares to control, RV+3NP OS and VE+3NP OS group. 


\section{International Journal of Biochemistry \& Physiology}

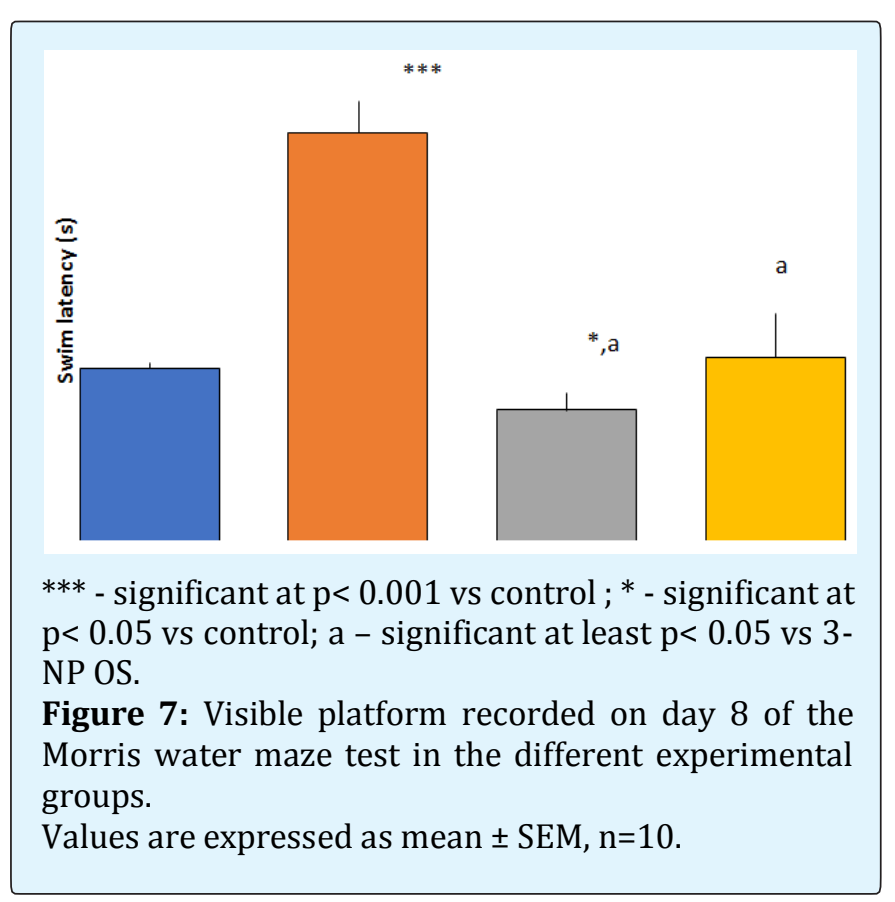

\section{Discussion}

This research work was aimed at investigating the effect of $R$. vomitoria and Vitamin $\mathrm{E}$ on learning and memory in 3-Nitropropionic acid-induced oxidative stressed mice using Morris water maze.

Learning and memory in mice can be assessed using Morris water maze test [31]. Morris water maze test is a test of visuo-spatial learning and memory. Here, mice were taught to locate the hidden platform using a unique intra-maze cue. During the acquisition and reversal training, the swim latency is measured and this swim latency are the time it take for the mice to swim and locate the hidden platform. Animals with longer swim latency are not able to learn fast to locate the hidden platform as quickly as those with shorter swim latency [32]. The animals treated with 3NP OS had longer swim latency when compared with the control, suggesting they were not able to learn very well, and when compared with $\mathrm{RV}+3 \mathrm{NP}$ OS and VE+3NP OS, the swim latency was longer $[33,34]$. However, when the 3NP OS mice were treated with $R$. vomitoria and vitamin $\mathrm{E}$, the swim latency was shorter i.e. there was no significant difference from the control suggesting the animals were able to learn fast.

During the probe trial day, which was done without the hidden platform, the quadrant duration was measured. Quadrant duration is the amount of time spent in each quadrant during the probe trial. The quadrant that has the hidden platform during the reversal training is referred to as the retention quadrant. Here, an animal that has memory of the hidden platform will spend much time swimming around the quadrant that has the hidden platform during the reversal which means the animal has learnt well $[35,36]$. In this study, it was observed that following induction of oxidative stress in mice using 3NP, the quadrant durations both in acquisition quadrant and retention quadrant were significantly lower in the oxidative stressed (3NP OS) group compared to control. This implied that there was memory impairment following induction of oxidative stress in mice. This buttressed the fact that oxidative stress leads to memory impairment as seen in Alzheimer's disease [37,38]. However, following treatment with the root bark extract of $R$. vomitoria and vitamin E, this impairment was reversed. This was shown in the increased quadrants durations, both in the acquisition and reversal or retention quadrants [39]. The root extract of $R$. vomitoria seemed to have been more effective in reducing the memory impairment when compared with vitamin E. Therefore, these results suggest that both $R$. vomitoria and vitamin $E$ resversed memory impairment induced by oxidative stress but $R$. vomitoria seemed more potent.

\section{Conclusion}

The impaired cognitive learning and memory caused by 3NP-induced oxidative stress in mice as shown in the MWM test were reversed with the root bark extract of $R$. vomitoria and Vitamin E toward normal, with $R$. vomitoria being more potent in ameliorating the effect of oxidative stress on learning and memory.

\section{References}

1. Osim EE (2008) "Element of Neurophysiology". $3^{\text {rd }}$ (Edn.), University of Calabar Press, Calabar.

2. Mayer RE (2001) "Multimedia learning," New York: Cambridge University Press.

3. Olds J, Milner P (1954) Positive reinforcement produced by electrical stimulation of septal area and other regions of rat brain. J Comp Physiol Psychol 47(6): 419-427.

4. Bliss TV, Lomo T (1973) Long-lasting potentiation of synaptic transmission in the dentate area of the anaesthetized rabbit following stimulation of the perforant path. J Physiol 232(2): 331-356. 


\section{International Journal of Biochemistry \& Physiology}

5. Chen C, Tonegawa S (1997) Molecular genetic analysis of synaptic plasticity, activity- dependent neural development, learning and memory in the mammalian. Annu Rev Neurosci 20: 157-184.

6. Basbaum AI (1996) Memories of pain. Science and Medicine, pp: 22-31.

7. LeDoux JE (1994) Emotion, memory and the brain. Sci Am 270(6): 50-57.

8. Alston TA, Mela L, Bright HJ (1977) 3Nitropropionate, the toxic substance of indigofera, is a suicide inactivator of succinate dehydrogenase. Proc Natl Acad Sci USA 74(9): 3767-3771.

9. Beal MF (2012) Mitochondrial dysfunction in neurodegenerative diseases. J Pharmacol Exp Ther 342(3): 619-630.

10. Maya-López M, Colín-González AL, Aguilera G, de Lima ME, Colpo-Ceolin A, et al. (2017) Neuroprotective effect of WIN55,212-2 against 3nitropropionic acid-induced toxicity in the rat brain: involvement of CB1 and NMDA receptors. Am J Transl Res 9(2): 261-274.

11. Combs GF (1992) The Vitamins. Fundamental Aspects in Nutrition and Health. Academic Press, Inc. USA, pp: 63.

12. Institute of Medicine (2000) Dietary Reference Intakes for vitamin $\mathrm{C}$, vitamin $\mathrm{E}$, Selenium and Carotenoids. Washington DC. The National Academies Press, pp: 186-283.

13. Ehiagbonare EJ Regeneration of Rauwolfia vomitoria. African Journal of Biotechnology 6(8): 979-981.

14. Boun D (1995) Encyclopedia of Herbs and their uses. DK Publishing Inc. New York, pp: 65-68.

15. Cragg GM (1998) Testimony. In: Pamplona-Roger GD (Ed.), Encyclopedia of Medicinal Plants. Madrid 2: 37408.

16. James SB, Owolabi AO, Ibiyeye H, Magaji J, Ikugiyi YA (2008) Assessment of the hepatic effects, haematological effect and some phytochemical constituents of Ximenia Americana (Leaves, stem and root) extracts. African Journal of Biotechnology 7(23): 4274-4278.
17. Amole 00, Onabanjo AO (1999) Antipyretic effect of the extract of Rauvolfia vomitoria (Afzel) in rabbits. Nigerian Journal of Natural Products and Medicine 3: 77-78.

18. Amole 00, Onabanjo AO, Odofin AA (2006) The analgesic effect of Rauvolfia vomitoria (Afzel). Biomed Research International 17: 125-127.

19. Amole OO, Yemitan OK, Oshikoya KA (2009) Anticonvulsant activity of Rauvolfia vomitoria (Afzel). African Journal of Pharmacy and Pharmacology 3(6): 319-322.

20. Bisong SA, Brown RE, Osim EE (2013) Comparative extrapyramidal effects of Rauwolfia vomitoria, chlorpromazine and reserpine in mice. J Nat Med 67(1): 107-112.

21. Eluwa MA, Idumesaro NB, Ekong MB, Akpantah AO, Ekanem TB (2009) Effect of aqueous extract of Rauwolfia vomitoria root bark on the cytoarchitecture of the cerebellum and neurobehaviour of adult male Wistar rats. Internet Journal of Alternative Medicine 6: 8.

22. Bisong SA, Brown R, Osim EE (2010) Comparative effects of Rauwolfia vomitoria and chlorpromazine on locomotor behaviour and anxiety in mice. J Ethnopharmacol 132(1): 334-339.

23. Kweifio-Okai G, Bird D, Field B, Ambrose R, Carroll AR, et al. (1995) Anti-inflammatory activity of a Ghanaian antiarthritic herbal preparation: III. J Ethnopharmacol 46(1): 7-15.

24. Campbell JI, Mortensen A, Molgaard P (2006) Tissue lipid lowering-effect of a traditional Nigeian antidiabetic infusion of Rauwolfia vomitoria foliage and Citrus aurantium fruit. J Ethnopharmacol 104(3): 379-386.

25. Akpanabiatu MI, Uboh FE, Ekanem TB, Umoh IB, Eyong EU, et al. (2009) The effect of interaction of Rauwolfia vomitoria root bark extract with vitamin E on rats liver enzymes. Turkish Journal of Biology 33: 189-194.

26. Bemis DL, Capodice JL, Gorroochurn P, Katz AE, Buttyan R (2006) Anti-prostate cancer activity of $\beta$ carboline alkaloid enriched extract from Rauwolfia vomitoria. Int J Oncol 29(5): 1065-1073. 


\section{International Journal of Biochemistry \& Physiology}

27. Bisong S, Brown R, Osim E (2011) Comparative effects of Rauwolfia vomitoria and chlorpromazine on social behaviour and pain. N Am J Med Sci 3(1): 4854.

28. McDonald RJ, White NM (2004) Parallel information processing in the water maze: evidence for independent memory systems involving dorsal striatum and hippocampus. Behav Neural Biol 61(3): 260-270.

29. Iivonen H, Nurminen L, Harri M, Tanila H, Puoliväli J (2003) Hypothermia in mice tested in moris water maze. Behav Brain Res 141(2): 207-213.

30. Wong AA, Brown RE (2007) Age-related changes in visual acuity, learning and memory in C57BL/6J and DBA/2J mice. Neurobiol Aging (10): 1577-1593.

31. Morris R (1984) Developments of a water-maze procedure for studying spatial learning in the rat. J Neurosci Methods 11(1): 47-60.

32. Acosta S, Jernberg J, Sanberg CD, Sanberg PR, Small BJ, et al. (2010) NT-020, a natural therapeutic approach to optimize spatial memory performance and increase neural progenitor cell proliferation and decrease inflammation in the aged rat. Rejuvenation Res 13(5): 581-588.

33. Rocher MN, Carré D, Spinnewyn B, Schulz J, Delaflotte $S$, et al. (2011) Long-term treatment with standardized ginkgo biloba extract (EGb 761) attenuates cognitive deficits and hippocampal neuron loss in a gerbil model of vascular dementia. Fitoterapia 82(7): 1075-1080.

34. Wang J, Chen W, Wang Y (2013) A ginkgo biloba extract promotes proliferation of endogenous neural stem cells in vascular dementia rats. Neural Regen Res 8(18): 1655-1662.

35. Tambuyzer BR, Ponsaerts P, Nouwen EJ (2009) Microglia: gatekeepers of central nervous system immunology. J Leukoc Biol 85(3): 352-370.

36. Ihl R, Tribanek M, Bachinskaya N; GOTADAY Study Group (2012) Efficacy and tolerability of a once daily formulation of ginkgo biloba extract EGb 761® in Alzheimer's disease and vascular dementia: results from a randomised controlled trial. Pharmacopsychiatry 45(2): 41-46.

37. Bertram L, Lill CM, Tanzi RE (2010) The genetics of Alzheimer disease: back to the future. Neuron 68(2): 270-281.

38. Chaitanya KV, Pathan AAK, Mazumdar SS, ChakRavarthi GP, Parine N, et al. (2010) Role of oxidative stress in human health: An overview. Journal of Pharmacy Research 3: 1330-1333.

39. Ekong MB, Ekpene UU, Thompson FE, Peter AI, Udoh NB, et al. (2015) Effects of co-treatment of Rauwolfia vomitoria and Gongronema latifolium on neurobehaviour and the neurohistology of the cerebral cortex in mice. Internet Journal of Medical Update 10(1): 3-10.

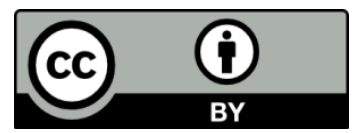

Eze Ejike D, et al. Rauwolfia Vomitoria and Vitamin E Restore Impaired Learning and Memory in 3-Nitropropionic Acid-Induced Oxidative 